\title{
Incubation Time Measurements in Thin-Film Deposition
}

\author{
J. B. Rem," J. Holleman,"* and J. F. Verweij \\ MESA Research Institute, University of Twente, NL-7500 AE Enschede, The Netherlands
}

\begin{abstract}
Studies on the initial growth or nucleation of materials and research on selective deposition often mention an incubation time. Many techniques exist to determine the incubation time. The outcome can be very different for each technique when the same nucleation process is considered. For the first time we have given a simple model which shows that several incubation times can be expected if different methods are used. One of the most popular methods, plotting the mass or thickness as a function of time and defining the incubation time as the intercept on the $x$-axis, is not a good method. In particular, a meaningful incubation time is found only if a layer-by-layer growth mechanism occurs right from the start. Ellipsometry can be used in situ and is a much more sensitive method, but this technique needs more research to correlate the nucleation process with the data obtained using this technique. The determination of the nucleus density using scanning electron microscopy or atomic force microscope is the most accurate method, yet needs a lot of experiments. Without a detailed description of the measurement method the incubation time is a meaningless quantity.
\end{abstract}

\section{Introduction}

In the case of deposition of thin films by means of chemical vapor deposition (CVD) or physical vapor deposition (PVD) one often observes a time delay in the formation of the thin film, also called incubation time. ${ }^{1-5}$ Eventually, the incubation time and nucleus growth determine the surface morphology and the electrical behavior of the film. Another issue for which the incubation time plays an important role is selective growth. The incubation time may depend on the combination of thin-film and substrate $^{6}$ and on deposition parameters. When the delay is strongly dependent on the combination of the thin-film and substrate it offers the possibility of selective growth. ${ }^{7}$ In integrated circuits (IC) technology examples are the CVD of $\mathrm{Si},{ }^{5} \mathrm{Ge},{ }^{7}$ germanium-silicon $\left(\mathrm{Ge}_{x} \mathrm{Si}_{1-x}\right)$ alloys ${ }^{8}$ and W. ${ }^{9}$ These materials, when deposited by CVD, have a tendency of growing after a short incubation time on $\mathrm{Si}$, whereas the incubation time on $\mathrm{SiO}_{2}$ and $\mathrm{Si}_{3} \mathrm{~N}_{4}$ is longer.

The deposition of polycrystalline silicon (poly-Si) and $-\mathrm{Ge}_{x} \mathrm{Si}_{1-x}$ involves a complex combination of several processes. Among these processes are the arrival and removal of gas molecules or precursors at the substrate surface, the decomposition into reactive species, and the migration of these reactive species on the surface where they can lead to nucleation and continued deposition. ${ }^{10}$ The adsorbed reactive species are likely to come to rest when a position of minimum energy is found. These minimum energy positions can be a defect at the substrate surface, which will result in a new nucleus, or an existing nucleus, which will subsequently grow. ${ }^{11}$ For certain process conditions the formation of nuclei is delayed for some time, known as the incubation time. ${ }^{10}$

Different combinations of arrival rate and surface migration can lead to different film morphologies and structures, which will have their impact on device performance and reliability. ${ }^{12,13}$ The arrival rate of reactive species to the surface and the surface mobility depend on the substrate surface condition, partial pressure of reactive (and if present carrier) gas and temperature, if CVD is considered. Amorphous films are usually obtained from a high nucleus density resulting from a high arrival rate and low adatom surface mobility, while polycrystalline material is obtained from a lower nucleus density resulting from a low arrival rate and high surface mobility.

It is apparent that the initial growth and structural properties of the film are strongly dependent on the deposition parameters, as well as reactor geometries, purity of the chemicals, pump oil back-diffusion, and reactor leak rate. All these will affect the electrical behavior of devices fabricated in these films. Therefore, the initial growth of poly-Si and $-\mathrm{Ge}_{x} \mathrm{Si}_{1-x}$ has been investigated. ${ }^{14}$

The incubation time can be determined with several techniques. Unfortunately, different methods can result in

* Electrochemical Society Student Member. deviating incubation times for equal process conditions, which makes comparison of data in the literature difficult, if not meaningless.

In this paper, an overview of existing measurement methods is presented. These are illustrated with experimental data on rapid thermal chemical vapor deposited (RTCVD) poly-Si and $-\mathrm{Ge}_{0.3} \mathrm{Si}_{0.7}$. Then, a nucleation model is given which calculates nucleation parameters of the growing film. After this, several "apparent" incubation times are calculated and compared to measurements according to the different methods.

\section{Methods to Assess IncubationTime}

In this paper the incubation time is defined as the time difference between the start of the deposition process and the onset of formation of the first nuclei. The size of the initial nuclei is of atomic dimensions and their initial number is small. Many techniques to determine the incubation time have been reported in the literature. The results of the techniques yield "apparent" incubation times that may differ a lot from the incubation time. The techniques can be roughly divided as follows.

Step height measurement methods.-A very popular method is to etch a step in the deposited layer and determine the step height with a surface profilometer. Extrapolation of the linear part of the thickness $v s$. time yields the incubation time..$^{5,15-17}$ This is a simple technique, yet unsuitable for in situ measurements. Furthermore, its resolution is generally not accurate enough to observe changes in the beginning of the growth process when the film is not completely closed. ${ }^{15}$

Gravimetrical methods.-These methods concern the use of (micro)balances. The resolution is about $10 \mu \mathrm{g}$ and the incubation time could be defined as the time needed to obtain this weight change, or one could extrapolate the linear part of the mass $v s$. time plot to zero mass. ${ }^{14}$

Microscopic methods.-The resolution of optical and electron microscopes is highly dependent on the contrast. In general, this is too low for silicon nucleation on an oxidized silicon wafer when an optical microscope is used. Dark-field microscopy is a method with improved contrast but this is still insufficient for the observation of Si nuclei on a substrate consisting of a thin-oxidized Si wafer. Laser microscopy is a new development in microscopy methods exhibiting a much higher contrast. ${ }^{19}$

In case of a (high resolution) scanning electron microscope (HRSEM) with a resolution of $2 \mathrm{~nm}$ to gold nuclei, the resolution can be estimated to be about 6 to $10 \mathrm{~nm}$ for silicon nuclei. This allows for the determination of the nucleus density as a function of time. ${ }^{1,4,15}$

Atomic force microscopy (AFM) is a very useful tool ${ }^{13,20}$ and has a resolution close to atomic dimensions. Special arrangements are needed to prevent charging of the sample and deformation or removal of surface features of the 


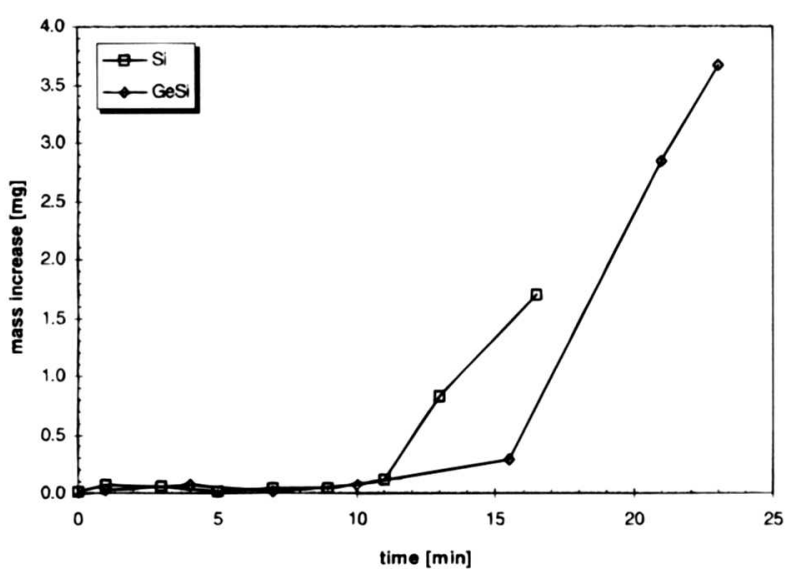

Fig. 1. Experimental mass as a function of deposition time for poly-Si at $625^{\circ} \mathrm{C}, 0.20$ mbar, and $35 \mathrm{sccm} \mathrm{SiH}_{4}$ and poly- $\mathrm{Ge}_{0.3} \mathrm{Si}_{0.7}$ at $550^{\circ} \mathrm{C}, 0.20 \mathrm{mbar}, 30 \mathrm{sccm} \mathrm{SiH} 4+5 \mathrm{sccm} \mathrm{GeH}_{4}$. The extrapolation of the linear plot results in a deposition rate of 0.28 and $0.45 \mathrm{mg} / \mathrm{min}$ while an incubation time of 11 and $15 \mathrm{~min}$ is found for $\mathrm{Si}$ and $\mathrm{Ge}_{0.3} \mathrm{Si}_{0.7}$, respectively.

unstable material such as the nuclei. Gold sputtering can be used to enhance charge-reduction via the tip of the needle but can still mask the very beginning of the growth process. Tapping mode sampling can significantly reduce these effects, thus allowing detailed information to be obtained. ${ }^{21-23}$

Transmission electron microscopy (TEM) also has a high resolution, which makes it very useful for the study of nucleation and early growth stages. ${ }^{24,25}$ The tedious sample preparation is a major drawback, although a recent study shows the use of in situ TEM to evaluate initial growth. ${ }^{26}$

Surface analysis methods.-This class of techniques includes surface spectroscopic methods like Auger electron spectroscopy (AES), x-ray photoelectron spectroscopy (XPS), total reflection $x$-ray fluorescence (TXRF), and Rutherford backscattering spectroscopy (RBS). The resolution generally depends on the deposited materials but may vary between $10^{10}$ and $10^{12}$ atom $/ \mathrm{cm}^{2}$.

Optical methods.-Using a light beam and measuring the reflected intensity gives a noncontacting method to observe changes at the surface. Also, the speed of this technique is high if the optical properties of the sample change when the deposition process progresses. Therefore, techniques such as reflectometry and ellipsometry are good candidates for in situ measurements..$^{20,27}$ The resolution depends, among others, on the sample preparation while the correlation with the nucleation process is not obvious. This is also a problem with the spectroscopic methods.

In this paper, we concentrate on the different "apparent" incubation times found using some of the techniques described above. It is shown that, depending on the technique to determine the incubation time, differences will be found for the same nucleation process. Also, equal incubation times can be found for two different nucleation processes. This means that, when comparing incubation times, the techniques used to determine the incubation time have to be considered carefully.

\section{Experimental}

To experimentally illustrate different incubation times obtained with the methods described above the deposition of poly-Si and $-\mathrm{Ge}_{03} \mathrm{Si}_{07}$ on a 3 in. wafer in a rapid thermal multiprocessing (RTMP) reactor is presented below. The deposition sequence is described in detail elsewhere. ${ }^{14}$ In short, the $\mathrm{Si}$ wafer is oxidized at $1050^{\circ} \mathrm{C}$ in 0.1 bar pure $\mathrm{O}_{2}$ resulting in $6 \mathrm{~nm}$ oxide. After this, the deposition takes place without braking vacuum conditions, thus insuring a clean surface. A constant power supply is used, corresponding to a deposition temperature of approximately 625 and $550^{\circ} \mathrm{C}$ for $\mathrm{Si}$ and $\mathrm{Ge}_{03} \mathrm{Si}_{07}$, respectively. A total pressure of 0.20 mbar with a pure VLSI grade $\mathrm{SiH}_{4}$ flow of $35 \mathrm{sccm}$ and $30 \mathrm{sccm} \mathrm{SiH}_{4}+5 \mathrm{sccm} \mathrm{GeH} 4$ is used.

\section{Results and Discussion}

Mass increase vs. time.-In Fig. 1 a plot of the mass increase as a function of the deposition time is shown. Two features can be extracted from this graph. First, the deposition rate (in $\mathrm{mg} / \mathrm{min}$ ) can be found as the slope of the plot, being $0.28 \mathrm{mg} / \mathrm{min}$ for $\mathrm{Si}$ and $0.45 \mathrm{mg} / \mathrm{min}$ for $\mathrm{Ge}_{0.3} \mathrm{Si}_{0.7}$. Converting this deposition rate to the more familiar unit $\mathrm{nm} / \mathrm{min}$ requires the use of a (bulk) density value of the materials and the covered area. Etch experiments show a 90 to 10 ratio of front and back side, indicating almost single-sided deposition. Hence, the area is assumed to be one 3 in. wafer side. Using $2.33 \mathrm{~g} / \mathrm{cm}^{3}$ for $\mathrm{Si}$, $5.32 \mathrm{~g} / \mathrm{cm}^{3}$ for $\mathrm{Ge}$, and a linear interpolation between these bulk densities results in an average density of $3.23 \mathrm{~g} / \mathrm{cm}^{3}$ for $\mathrm{Ge}_{03} \mathrm{Si}_{07}$. This leads to a deposition rate of 27 and $30 \mathrm{~nm} / \mathrm{min}$, respectively. Second, the intercept of the extra-polated slope with the $\mathrm{x}$-axis can be called incubation time. For the poly-Si deposition this results in an incubation time of 11 min while it is $15 \mathrm{~min}$ for $\mathrm{Ge}_{0.3} \mathrm{Si}_{0.7}$.

To illustrate the erroneous assumption of a linear layerby-layer growth from the start of the deposition process a SEM picture is given in Fig. 2 after an exposure time equal to the incubation time obtained from Fig. 3 but less than that obtained from Fig. 1. It shows the surface of an oxidized Si wafer after $9 \mathrm{~min}$ of exposure at $0.20 \mathrm{mbar} 35 \mathrm{sccm}$ $\mathrm{SiH}_{4}$ (left) and $10 \mathrm{~min}$ of 0.20 mbar $30 \mathrm{sccm} \mathrm{SiH}_{4}+5 \mathrm{sccm}$ $\mathrm{GeH}_{4}$ (right). Although the mass or thickness vs. time method is widely used it is clear from this picture that some deposition did take place prior to the incubation time. It can be seen that poly-Si exhibits many small nuclei, indicating a high nucleation rate and a low growth rate ${ }^{14}$ whereas $\mathrm{Ge}_{0.3} \mathrm{Si}_{0.7}$ shows a much lower nucleation rate and higher growth rate. This can be seen in Fig. 1 as well.

Reflectometry.-Using reflectometry the incubation time is measured as the time during which no change in reflection signal occurs. See Fig. 3 for a typical reflection signal with the start procedure, incubation period, and the growth. From this figure an incubation time for the poly-
Fig. 2. SEM image of the surface of poly-Si (leff) and polycrystalline $\mathrm{Ge}_{0.3} \mathrm{Si}_{0.7}$ (right) deposited on a substrate consisting of a $6 \mathrm{~nm}$ oxide layer on a Si wafer after $9 \mathrm{~min}$ of exposure to 0.20 mbar $35 \mathrm{sccm} \mathrm{SiH}_{4}$ at $625^{\circ} \mathrm{C}$ and $10 \mathrm{~min} 550^{\circ} \mathrm{C}$ $0.20 \mathrm{mbar} 30 \mathrm{sccm} \mathrm{SiH}_{4}$ $+5 \mathrm{sccm} \mathrm{GeH}$. These exposure times are taken from the reflectivity incubation time.
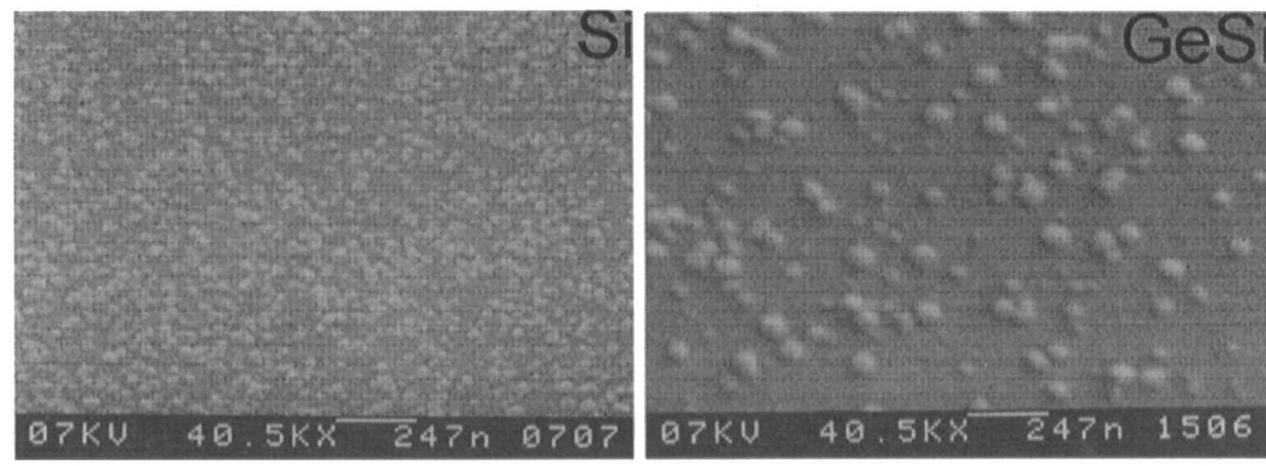


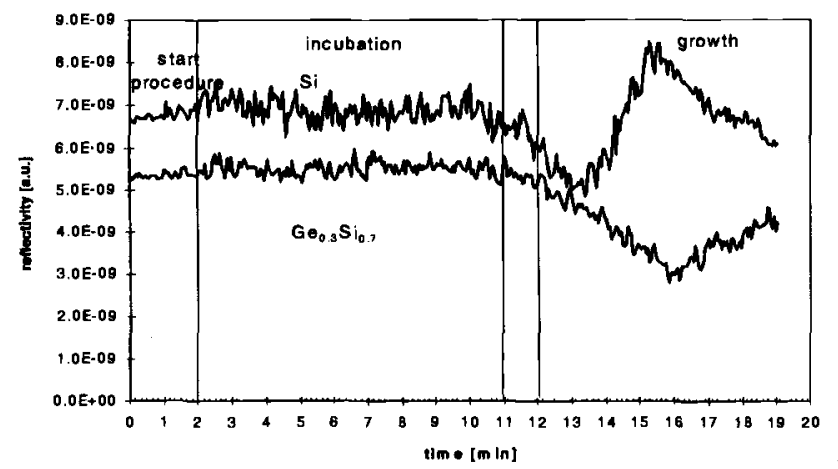

Fig. 3. Experimental reflectivity curve as a function of time for poly-Si deposition at $625^{\circ} \mathrm{C}, 0.20$ mbar using $35 \mathrm{sccm}$ pure $\mathrm{SiH}_{4}$, and polycrystalline $\mathrm{Ge}_{0.3} \mathrm{Si}_{0.7}$ deposition at $550^{\circ} \mathrm{C}, 0.20$ mbar, and $30 \mathrm{sccm} \mathrm{SiH}_{4}+5 \mathrm{sccm} \mathrm{GeH}$. The start procedure, incubation time, and growth are indicated in the figure. The incubation time is $9 \mathrm{~min}$ for $\mathrm{Si}$ and $10 \mathrm{~min}$ for $\mathrm{Ge}_{0.3} \mathrm{Si}_{0.7}$.

Si deposition of 9 and 10 min for poly- $\mathrm{Ge}_{0.3} \mathrm{Si}_{0,7}$ is found This is in reasonable agreement with the mass $v s$. time method, although, as discussed before with Fig. 2, nuclei are found within this incubation period.

The advantage of this method is that the in situ measurement is possible during nucleation and growth. One experiment is needed to obtain an incubation time which shows a reasonable agreement with the incubation time found by the mass vs. time method. This method does increase the understanding of the initial growth of materials but should be used in combination with other techniques.

Ellipsometry.-The ellipsometric quantity $\Delta$ is quite sensitive to changes at the surface ${ }^{20}$ in the case of $6 \mathrm{~nm}$ oxide on a $\mathrm{Si}$ wafer, as shown in Fig. 4. For poly-Si, it varies after $3 \mathrm{~min}$ while for polycrystalline $\mathrm{Ge}_{x} \mathrm{Si}_{1-x} 4 \mathrm{~min}$ are needed to obtain a significant change in $\Delta$. In the first stage the changes in $\Delta$ are small but measurable and indicate that ellipsometry is much more sensitive to changes at the surface compared to reflectometry. Therefore, this technique should be preferred where optical methods are available. Because it is a fast technique, an in situ ellipsometer can be implemented in monitoring the initial growth behavior of materials, although a correlation with the nucleation process needs to be established using a combination of methods. ${ }^{20,27}$

Nucleus density vs. time.-With today's equipment one can state that, using SEM, TEM, and AFM, nuclei with diameters just slightly larger than a few atoms can be found. So, this method seems a very accurate way to

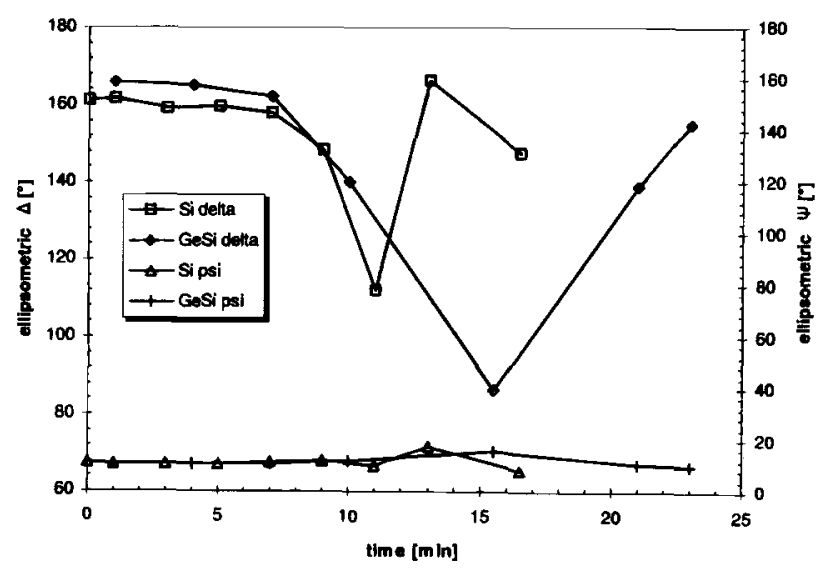

Fig. 4. Experimentally measured ellipsometric quantity $\psi$ and $\Delta$ as a function of time, using a $632.8 \mathrm{~nm}$ laser and an angle of incidence of $70^{\circ}$. An incubation time of $3 \mathrm{~min}$ for Si and $4 \mathrm{~min}$ for $\mathrm{Ge}_{0.3} \mathrm{Si}_{0.7}$ is found for a significant change in $\Delta$. obtain the incubation time. The drawback of these methods is the time-consuming preparation and the ex situ nature of the techniques.

The nucleus density and the size of the largest nuclei (since these are the oldest) are determined from SEM pictures like Fig. 2. A plot as shown in Fig. 5 is obtained. The incubation time is measured as the extrapolated intercept on the $\mathrm{x}$-axis, or as the time during which no nuclei are observed. The nucleation rate is measured from the slope of this curve. For the poly-Si and $\mathrm{Ge}_{x} \mathrm{Si}_{1-x}$ deposition the incubation time is 2 and $4 \mathrm{~min}$, respectively. The nucleation rate is estimated at $1 \cdot 10^{10}$ and $6 \cdot 10^{8}$ nuclei $/ \mathrm{cm}^{2} \mathrm{~min}$ while the nucleus radius growth rate is 2.5 and $6.5 \mathrm{~nm} / \mathrm{min}$, as shown in Fig. 5.

From Fig. 5 it is concluded that the incubation time for $\mathrm{Si}$ growth is $2 \mathrm{~min}$. It can also be observed that the nucleus density does not saturate, which is an indication that new nuclei are constantly formed. The nucleus density could not be established for deposition times larger than 9 min due to coalescence of nuclei. For $\mathrm{Ge}_{0.3} \mathrm{Si}_{0.7}$ the incubation time is 4 min.

\section{Modeling of Incubation Time}

To evaluate some of the different methods for determination of the incubation time, a model is given in this paragraph which describes the initial growth of Si on a Si wafer covered with a $6 \mathrm{~nm}$ thermal oxide. The following assumptions in our calculations of the surface coverage are used: (i) the incubation time is $0 \mathrm{~min}$; (ii) the rate of nucleus formation is proportional to the available free oxide surface; (iii) the nuclei grow as hemispheres and the growth rate is constant.

The assumption of zero incubation time is made to explain, that the difference in "apparent" incubation times obtained with the various techniques is a result of the different methods. The nucleus density does not saturate (as shown in Fig. 5) and the radius of the largest nuclei grows linearly with time. From this observation one might conclude that either the mean free path of surface adsorbed species is small or that the sticking probability of these surface species to existing nuclei is small. In the latter case the growth of the nuclei is determined by the hydrogen desorption (as is the case for poly-Si and poly$\mathrm{Ge}_{x} \mathrm{Si}_{1-x}$ growth) and not by the arrival rate of these species.

Nucleation growth model.-Nuclei are formed with a rate equal to NR (number of nuclei $/ \mathrm{cm}^{2} \mathrm{~min}$ ). The nucleus will grow in size with a rate GR $(\mathrm{nm} / \mathrm{min})$. While this

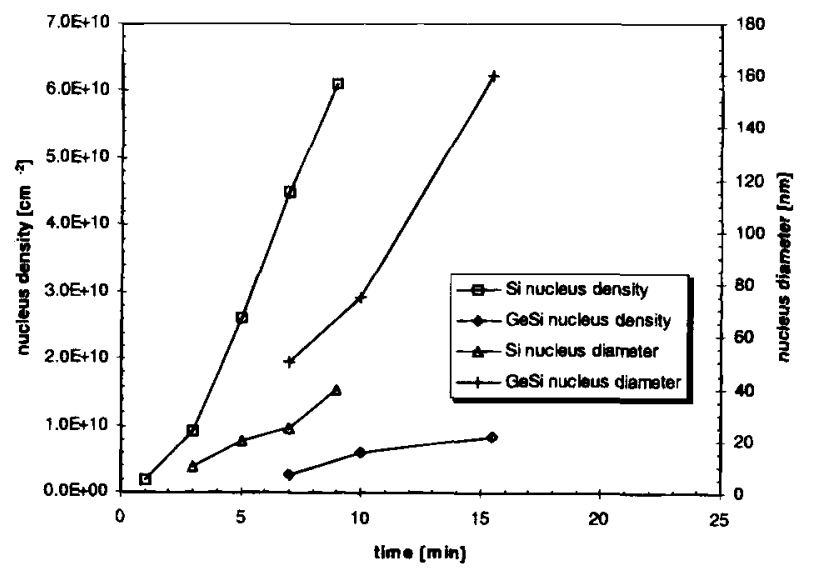

Fig. 5. Experimental nucleus density and nucleus diameter as a function of time determined from SEM pictures for poly-Si deposition at $625^{\circ} \mathrm{C}, 0.20 \mathrm{mbar}$, and $35 \mathrm{sccm} \mathrm{SiH}$, and poly- $\mathrm{Ge}_{0.3} \mathrm{Si}_{0.7}$ deposition at $550^{\circ} \mathrm{C}, 0.20 \mathrm{mbar}, 30 \mathrm{sccm} \mathrm{SiH}{ }_{4}+5 \mathrm{sccm} \mathrm{GeH}_{4}$. The nucleus formation rate and diameter growth rate are obtained from the slope of the curves yielding $1 \cdot 10^{10}$ nuclei $/ \mathrm{cm}^{2} \mathrm{~min}$ and $5 \mathrm{~nm} / \mathrm{min}$ for Si and $6 \cdot 10^{8}$ nuclei $/ \mathrm{cm}^{2} \mathrm{~min}$ and $13 \mathrm{~nm} / \mathrm{min}$ for $\mathrm{Ge}_{0.3} \mathrm{Si}_{0.7}$, respectively. 
nucleus is growing, new nuclei are formed with the nucleation rate NR at sites not already covered with Si nuclei. The area of the wafer covered with the deposited material as a function of time can be written as $A(t)=$ number of nuclei/unit area $\cdot$ size of the nuclei at time $t \cdot$ total wafer area, or

$$
A(t)=A w \cdot \sum_{i=0}^{\mathrm{t}} N R(i) \cdot \pi \cdot\left(r_{\text {nucleus }}(i)\right)^{2}
$$

where $A(t)$ is the total area covered with deposited material, $A w$ is the area of a single side of a 3 in. wafer $\left(45.6 \mathrm{~cm}^{2}\right), N R(i)$ is the nucleation rate at a time step $i$, and $r(i)$ is the radius of the hemispherically growing nucleus at time step $i$, which increases in time with the growth rate GR. The nucleation rate per unit area $N R(i)$ generally is a function of time and available free area. ${ }^{28} N R(i)$ can be written in the form

$$
N R(i)=N_{0}\left(\frac{A w-A(i-1)}{A w}\right)
$$

with $N_{0}$ as a constant nucleus forming rate per unit free area.

In the first stage of the nucleation process an adsorbedlayer (adlayer) is built up. Nuclei start to form when a critical surface density of adsorbed species is reached. This number increases proportionally with time and free surface area until a saturation point is reached. Further exposure does not increase the number of nuclei but leads to nucleus density saturation and only growth of existing nuclei until these start to coalesce. The point of saturation is determined by the mean free path $L=\sqrt{D \cdot \tau}$, where $D$ is the surface diffusion coefficient and $\tau$ is the average residence time, and the sticking probability of surface reactive species to existing nuclei. In our calculations a proportionality of NR to time and free surface is assumed. This is a reasonable assumption for $\mathrm{Si}$ and $\mathrm{Ge}_{x} \mathrm{Si}_{1-x}$ as can be concluded from Fig. 5.

Using Eq. 1 and Eq. 2 and writing $r(i)=r_{0}+G R \cdot i$ for the radius increase of the nucleus yields an expression for the total covered area of

$$
A(t)=A w \cdot \sum_{i=0}^{\mathrm{t}} N_{0}\left[\frac{A w-A(i-1)}{A w}\right] \cdot \pi \cdot\left(r_{0}+G R \cdot i\right)^{2}
$$

where $r_{0}$ is the critical radius of a nucleus in $\mathrm{nm}$ (the minimum radius necessary to define the cluster as a nucleus), $A(0)=0$, and $G R$ is the growth rate.

The volume of deposited $\mathrm{Si}$ is calculated using

$$
\begin{aligned}
V(t)=A w \cdot \sum_{i=1}^{t} N_{0} \cdot\left[\frac{A w-A(i-1)}{A w}\right] \\
\cdot \frac{2}{3} \cdot \pi \cdot\left(r_{0}+G R \cdot i\right)^{3}
\end{aligned}
$$

where $V(t)$ is the total volume of deposited material and $V(0)=0$.

Calculation of nucleation parameters.-In order to compare the different methods for determination of the incubation time the following properties are calculated: radius of the largest nuclei, total covered area, total deposited volume, volume fraction, mass, nucleus density, refractive index, reflection coefficient, and the ellipsometric quantities $\psi$ and $\Delta$. The nuclei that arise after the first time period, $t=1$, are assumed to grow at the same speed as nuclei arising at the time period te -1 . Then, the maximum size of a nucleus $r_{\max }$ at time $t$ is equal to $t \cdot G R$. Not all nuclei will have this size though, so a certain volume fraction can be defined using this maximum radius. The volume fraction $f_{\mathrm{Si}}$ is defined as the total volume of Si present in an effective medium with a thickness $d$ equal to the maximum radius. This leads to

$$
f_{\mathrm{Si}}=\frac{V(t)}{A w \cdot r_{\max }}
$$

From the volume fraction the effective density of this layer can be calculated by multiplying the volume fraction with the bulk density, assuming that bulk values can be applied to these thin films. Also, from the volume fraction, the refractive index can be calculated from the effective dielectric constant with the Bruggemans effective medium approximation. ${ }^{29,30}$ Using bulk values of the dielectric constant of air $\left(E_{\text {air }}=1.00\right)$ and of $\operatorname{Si}\left(E_{\mathrm{Si}}=14.822-0.146 \mathrm{i}\right.$ at room temperature) the effective dielectric constant of the film $E_{\text {eff }}$ is calculated from

$$
f_{\text {air }} \cdot \frac{E_{\text {air }}-E_{\text {eff }}}{E_{\text {air }}+2 \cdot E_{\text {eff }}}+f_{\mathrm{Si}} \cdot \frac{E_{\mathrm{Si}}-E_{\text {eff }}}{E_{\mathrm{Si}}+2 \cdot E_{\text {eff }}}=0
$$

with $f_{\text {air }}$ as the volume fraction of air and $f_{\text {air }}+f_{\mathrm{Si}}=1$. The refractive index of the film $n_{\text {film }}$ is

$$
n_{\text {film }}=\sqrt{E_{\text {eff }}}
$$

with $n_{\text {film }}=n_{\text {eff }}+i \cdot k_{\text {eff. }}$ The reflection coefficient $R(t)$ of the thin film is given by

$$
R(t)=\left(\frac{E_{1}^{-}}{E_{1}^{+}}\right)^{2}
$$

with $E_{1}^{-}$and $E_{1}^{+}$as the amplitudes of reflected and incident electric field vector at the first interface, respectively, ${ }^{31} R$ can be calculated by a matrix method ${ }^{32,33}$

A normalized reflectivity is calculated from the ratio of $R(t)$ and $R_{\text {sub }}$, where $R_{\text {sub }}$ is the reflectivity of the substrate consisting of a $6 \mathrm{~nm}$ oxide layer on a Si wafer and has a value of 0.344

The nucleus density is the sum of all arisen nuclei per unit area. The ellipsometric quantities $\psi$ and $\Delta$ are calculated from the calculated effective refractive index $n_{\text {eff }}$ and absorption coefficient $k_{\text {eff }}$ using Drude's approximation. ${ }^{34}$

While the nuclei are formed and growing in size a layer is formed with properties that are calculated below. The calculated properties are leading to "apparent" incubation time values according to the different techniques. In our calculations we have assumed that the incubation time is 0 .

Using Fig. 6a and $b$, we discuss mass, nucleus density, normalized reflectivity, and ellipsometric $\Delta v s$. time, thus comparing two combinations: a high nucleation rate-low growth rate and a low nucleation rate-high growth rate. This is further compared with the experimental results described above.

Calculation of incubation times.-Figure 6 a shows the calculated values of the above-mentioned film properties for a (relatively high) nucleation rate of $N=10^{10}$ nuclei $/ \mathrm{cm}^{2} \mathrm{~min}$ and a (low) growth rate of $G R=2 \mathrm{~nm} / \mathrm{min}$, while Fig. 6b shows the calculated values for a (low) nucleation rate of $6 \cdot 10^{8}$ nuclei/ $/ \mathrm{cm}^{2} \mathrm{~min}$ and a (high) growth rate of $8 \mathrm{~nm} / \mathrm{min}$. These values are taken from the SEM results in Fig. 2 and Fig. 5.

Extrapolation of the mass increase vs. time curve is not relevant since the model only describes the mass increase in the beginning of the growth process. Therefore, the mass increase is considered significant when it is larger than $0.10 \mathrm{mg}$. From Fig. 6a and b it is observed that the incubation time is $11 \mathrm{~min}$ while it is $8 \mathrm{~min}$ for the low nucleation rate-high growth rate combination. The nucleus density starts to increase after the first time step since we assumed an incubation time of $0 \mathrm{~min}$. Therefore, the calculated incubation time for the nucleus density is $0 \mathrm{~min}$.

The incubation time found with reflectometry is $11 \mathrm{~min}$ for the high nucleation rate-low growth rate combination while it is $7 \mathrm{~min}$ for the low nucleation rate-high growth rate combination if the reflectivity change is considered significant when it is larger than $5 \%$. The difference with the experimentally obtained incubation time (9 and 11 min for $\mathrm{Si}$ and $\mathrm{Ge}_{x} \mathrm{Si}_{1-x}$, respectively) is probably due to 

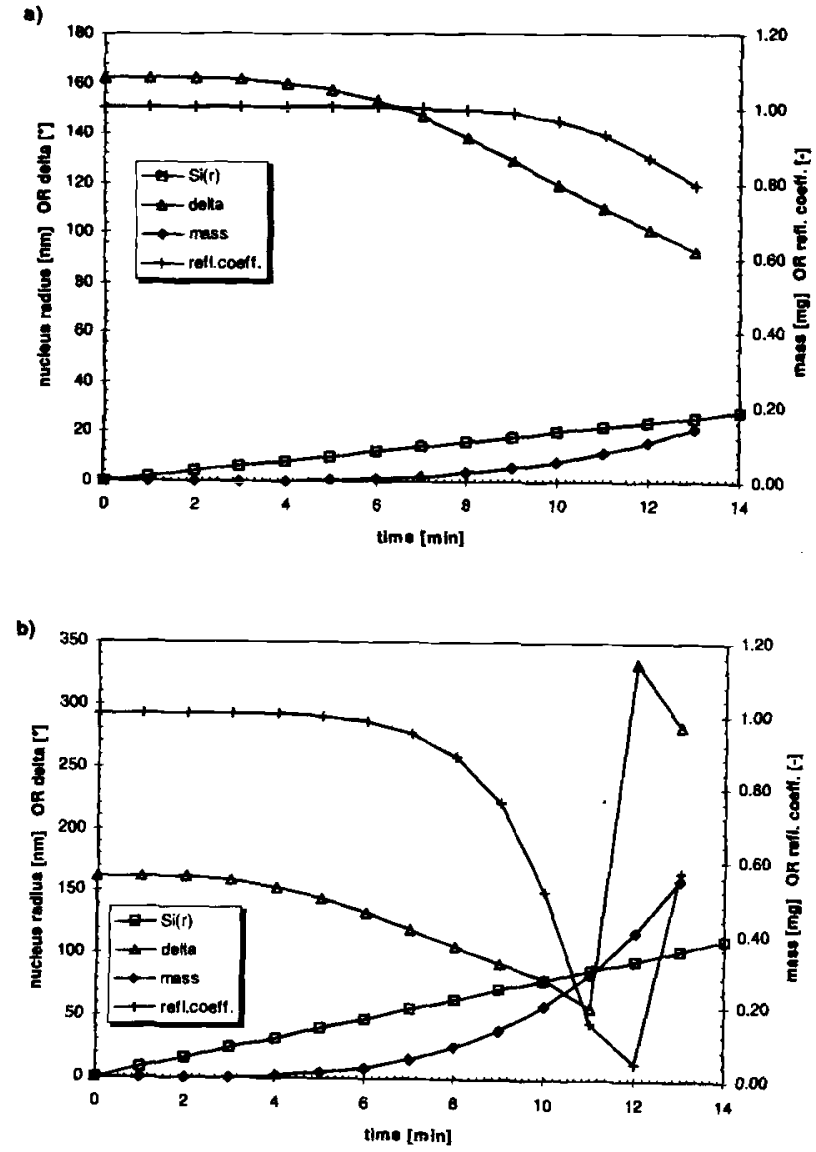

Fig. 6. Calculated film properties for a growing film using (a) a high nucleation rate of $1 \cdot 10^{10}$ nuclei/ $\mathrm{cm}^{2} \mathrm{~min}$ and a low growth rate of $2 \mathrm{~nm} / \mathrm{min}$ and (b) a low nucleation rate of $6 \cdot 10^{8}$ nuclei $/ \mathrm{cm}^{2}$ $\mathrm{min}$ and a high growth rate of $8 \mathrm{~nm} / \mathrm{min}$. These values are based on the experimental data of Fig. 5 .

a temperature enhanced growth rate and reflectivity change not included in this model. Still, a difference is expected according to the model while experimentally the incubation time is roughly equal for different nucleation processes.

The ellipsometric quantities $\Delta$ and $\psi$ change with the growth as well, $\psi$ much slower than $\Delta$, as shown in Fig. 4 . Defining a $2^{\circ}$ change in $\Delta$ significant leads to incubation times of 4 and $2 \mathrm{~min}$, respectively. The experimental incubation times are approximately equal for two different nucleation processes, which is in close agreement with the calculations.

In Table I the calculated and experimentally obtained incubation times are summarized to illustrate the different outcome for each technique. All four techniques result in a different incubation time, making comparison a troublesome task. Also, for two quite different nucleation processes (poly-Si and polycrystalline $\mathrm{Ge}_{x} \mathrm{Si}_{1-x}$ deposition) equal incubation times are found for the reflectivity and ellipsometric method. This demonstrates that the incubation time measurement and nucleation process parameters extrapolated from the incubation time need careful examination before any comparison is made.

The above clearly shows that a variety of incubation times is found for the same nucleation process if different methods are used to determine the incubation time. Also, two quite different nucleation processes can exhibit the same incubation time, all depending on the method of determination.

\section{Conclusions}

Many techniques to determine the incubation time exist. The outcome can be very different for each technique when the same nucleation process is considered. We have shown that one of the most popular methods, plotting the mass or thickness as a function of time and defining the incubation time as the intercept on the $\mathrm{x}$-axis, is not a good method. In particular, only if a layer-by-layer growth mechanism occurs right from the start can an incubation time be found.

Ellipsometry is a much more sensitive method, although correlating the ellipsometric data to the nucleation process requires more research and a combination with other techniques

In our opinion the best and most accurate technique is to determine the nucleus density from pictures, preferably taken with a (HR)SEM. Although this requires many experiments with $e x$ situ observations of the surface, this results in an incubation time during which no nuclei are found on the surface, whereas other methods do miss the early stage of growth.

Therefore, the incubation time should always be mentioned with a detailed description of the method used to determine this period. If mentioned alone, it is a meaningless quantity.

\section{Acknowledgments}

P. Boos is kindly acknowledged for assisting this work. J. H. Klootwijk and C. Salm are thanked for fruitful discussions, while M. H. H. Weusthof is thanked for assisting the RTMP experiments.

Manuscript submitted April 8, 1996; revised manuscript received March 21, 1997

The University of Twente assisted in meeting the publication costs of this article.

\section{REFERENCES}

1. K. E. Violette, M. K. Sanganeria, M. C. Öztürk, G Harris, and D. M. Maher, This Journal, 141, 3269 (1994)

2. H. C. Lin, C. Y. Chang, W. H. Chen, W. C. Tsai, T. C. Chang, T. G. Jung, and H. Y. Lin, ibid., 141, 2559 (1994).

3. J. T. Fitch, ibid., 141, 1046 (1994).

4. M. Kato, T. Sato, J. Murota, and N. Mikoshiba, J. Cryst. Growth, 99, 240 (1990).

5. J. Murota, N. Nakamura, M. Kato, N. Mikoshiba, and T. Ohmi, Appl. Phys. Lett., 54, 1007 (1989).

6. W. A. P. Claassen and J. Bloem, This Journal, 128, 1353 (1981).

7. H. Ishii, Y. Takahashi, and J. Murota, Appl. Phys. Lett., 47, 863 (1985).

\section{Table I. Summary of the calculated and experimental incubation times. The calculated incubation times are obtained using a nucleation rate of $1 \cdot 10^{10}$ nuclei/ $\mathrm{cm}^{2} \mathrm{~min}$, a growth rate of $2 \mathrm{~nm} / \mathrm{min}$, and an incubation time of 0 min for the high nucleation rate-low growth rate combination while $6 \cdot 10^{8}$ nuclei $/ \mathrm{cm}^{2} \mathrm{~min}, 8 \mathrm{~nm} / \mathrm{min}$, and an incubation time of $\mathbf{0}$ min are used for the low nucleation rate-high growth rate combination.}

\begin{tabular}{|c|c|c|c|c|}
\hline Method & $\begin{array}{l}\text { Calculated incubation time } \\
\text { (high nucleation rate- } \\
\text { low growth rate) }\end{array}$ & $\begin{array}{l}\text { Calculated incubation time } \\
\text { (low nucleation rate- } \\
\text { high growth rate) }\end{array}$ & $\begin{array}{l}\text { Experimental } \\
\text { incubation time } \\
\text { Si }\end{array}$ & $\begin{array}{c}\text { Experimental } \\
\text { incubation time } \\
\mathrm{Ge}_{0.3} \mathrm{Si}_{0.7}\end{array}$ \\
\hline $\begin{array}{l}\text { Mass } \\
\text { Reflectivity } \\
\text { Ellipsometry } \\
\text { Nucleus density }\end{array}$ & $\begin{array}{r}11 \\
11 \\
3 \\
0\end{array}$ & $\begin{array}{l}8 \\
7 \\
3 \\
0\end{array}$ & $\begin{array}{r}11 \\
9 \\
3 \\
2\end{array}$ & $\begin{array}{r}15 \\
11 \\
4 \\
4\end{array}$ \\
\hline
\end{tabular}


8. M. C. Öztürk, Y. Zhong, D. T. Grider, M. Sanganeria, J. J. Wortman, and M. A. Littlejohn, in Rapid Thermal and Related Processing Techniques, Vol. 1393, p. 260, SPIE-Int. Soc. Opt. Eng. (1990).

9. E. K. Broadbent and C. L. Ramiller, This Journal, 131, 1427 (1984).

10. T. I. Kamins, Polycrystalline Silicon for Integrated Circuit Applications, p. 43, Kluwer Academic Publishers, Boston, MA (1988).

11. A. C. Tickle, Thin-Film Transistors, A New Approach to Microelectronics, p. 14, John Wiley \& Sons, New York (1969).

12. H. Sehil, H. Lhermitte, F. Raoult, and Y. Colin, SolidState Electron., 37, 159 (1994).

13. H. Takahashi and Y. Kojima, Appl. Phys. Lett., 64, 2273 (1994).

14. J. B. Rem, C. Salm, H. J. Klootwijk, M. H. H. Weusthof, J. Holleman, and J. F. Verweij, MRS Proc., 387, 323, (1995).

15. M. Racanelli and D. W. Greve, Appl. Phys. Lett., 58 2096 (1991).

16. H.-C. Lin, H.-Y. Lin, C.-Y. Chang, T.-F. Lei, P. J. Wang, and C.-Y. Chao, ibid., 63, 1351 (1993).

17. J.-W. Kim, M.-K. Ryu, K.-B. Kim, and S.-J. Kim, This Journal, 143, 363 (1996).

18. S. S. Dana, M. Liehr, M. Anderle, and G. W. Rubloff, Appl. Phys. Lett., 61, 3035 (1992).

19. T. Kobayashi, M. Koguchi, S. Iijima, M. Ohkura, and Y. Wada, This Journal, 141, 1365 (1994).
20. H. N. Wanka, A. Hierzenberger, and M. B. Schubert, MRS Proc., 377, 263 (1995).

21. Y. Murakami, K. Naoi, K. Yahikozawa, and Y. Takasu, This Journal, 141, 2511 (1994).

22. B. J. Hwang and S. H. Lin, ibid., 142, 3749 (1995).

23. E. Gómez, E. Vallés, P. Gorostiza, J. Servat, and F. Sanz, ibid., 142, 4091 (1995).

24. K. Fujinaga, ibid., 142, 2341 (1995).

25. M. Otobe and S. Oda, J. Non-Cryst. Sol., 164-166, $993(1993)$

26. J. P. Guillemet, B. De Mauduit, B. Pieraggi, E. Campo, and E. Scheid, J. Mater. Sci. Lett., 12, 910 (1993).

27. M. Li, Y. Z. Hu, E. A. Irene, L. Liu, K. N. Christensen, and D. M. Maher, J. Vac. Sci. Technol. B., 13 105 (1995)

28. J. R. Frade, J. Mater. Sci., 29, 169 (1994).

29. D. E. Aspnes, J. B. Theeten, and F. Hottier, Phys. Rev. $B, 20,3292$ (1982).

30. D. A. G. Bruggeman, Ann. Phys. (Leipzig), 24, 636 (1935).

31. J. Holleman, A. Hasper, and J. Middelhoek, This Journal, 138, 783 (1991).

32. C. v. d. Laan and J. J. Franken, Appl. Opt., 17, 538 (1978).

33. A. Vasicek, Optics of Thin Films, North-Holland, Amsterdam (1960).

34. P. Drude, Ann. Phys. Chem. (Leipzig), 36, 532 (1989).

\title{
Reduction of Recombination Velocity on GaAs Surface by Ga-S and As-S Bond-Related Surface States from $\left(\mathrm{NH}_{4}\right)_{2} \mathrm{~S}_{x}$ Treatment
}

\author{
H. Sik, ${ }^{a}$ Y. Feurprier, ${ }^{b}$ C. Cardinaud, ${ }^{b}$ G. Turban, ${ }^{b}$ and A. Scavennec ${ }^{a}$ \\ ${ }^{a}$ Centre National d'Etudes des Télécommunications, Laboratorie de Bagneux, 92220 Bagneux Cedex, France \\ ${ }^{b}$ Laboratorie des Plasmas et des Couches Minces, IMN UMR 110 CNRS, Université de Nantes, \\ 44322 Nantes Cedex 03, France
}

\section{ABSTRACT}

A complete characterization of the GaAs surface treated with $\left(\mathrm{NH}_{4}\right)_{2} \mathrm{~S}_{x}$ solution is investigated in order to explain the bandedge photoluminescence improvement of the GaAs surface observed after sulfur treatment. Photoluminescence, surface-state density, and surface chemistry of the $\left(\mathrm{NH}_{4}\right)_{2} \mathrm{~S}_{x}$-treated GaAs surface are analyzed and compared with results from the literature. It is shown that the photoluminescence intensity is not directly controlled by surface-state density at midgap but seems to be correlated with the formation of sulfur bonds such as As-S and Ga-S, which are believed to create surface traps in the bandgap located near the valence band maximum and which appear to control band bending near the surface. To the authors' knowledge, this is the first experimental proof of such implication of the Ga-S and As-S bonds in the improvement of the GaAs surface electrical quality.

\section{Introduction}

Extensive literature has been published on the improvement of GaAs surface/interface electrical characteristics by chemical treatment using $\left(\mathrm{NH}_{4}\right)_{2} \mathrm{~S}_{x}$ solution. Treating the GaAs surface with $\left(\mathrm{NH}_{4}\right)_{2} \mathrm{~S}_{x}$ solution has been shown to be effective in (i) photoluminescence (PL) enhancement, ${ }^{1}$ (ii) realizing a dependence of Schottky barrier height on the metal work function, ${ }^{2}$ and (iii) improvements in capacitance-voltage characteristics of metal insulator semiconductor (MIS) structures fabricated with oxide-related insulator. ${ }^{3,4}$ These results have been attributed to the unpinning of the surface Fermi level, as a consequence of a GaAs surface-state density reduction associated with excess elemental As, which is presumably etched away by the aqueous sulfur solutions. However, although numerous spectroscopic and electrical studies of $\mathrm{Na}_{2} \mathrm{~S}$ and $\left(\mathrm{NH}_{4}\right)_{2} \mathrm{~S}_{x}$ treatments of the GaAs surface have been performed, variation of the induced chemical surface bonds, ${ }^{5}$ varying sta-

* Electrochemical Society Active Member. bility of the PL yield when exposed to air, and incomplete dependence of Schottky barrier height on metal work function ${ }^{6}$ make the mechanism of surface passivation in the $\mathrm{GaAs} /\left(\mathrm{NH}_{4}\right)_{2} \mathrm{~S}_{x}$ system still controversial.

Although numerous studies exist on the GaAs/ $\left(\mathrm{NH}_{4}\right)_{2} \mathrm{~S}_{x}$ system, few gather and compare surface chemistry, PL yield, and electrical characterization of the treated GaAs surface. In this work, we report on a systematic characterization of the $\left(\mathrm{NH}_{4}\right)_{2} \mathrm{~S}_{x} / \mathrm{GaAs}$-treated surface by monitoring the effects of annealing the $\left(\mathrm{NH}_{4}\right)_{2} \mathrm{~S}_{x} \mathrm{GaAs}$-treated surface on PL intensity, surface chemistry, and interface state density of TiAu/ $/ \mathrm{SiN}_{x} / \mathrm{GaAs}$ MIS structures (i.e., without oxide insulator). These experiments have enabled us to probe for the first time correlations between the improvement in PL intensity and the surface chemistry induced by the $\left(\mathrm{NH}_{4}\right)_{2} \mathrm{~S}_{2}$ treatment. The results suggest that the PL yield is controlled by the surface Fermi level shift toward the valence band maximum (VBM) associated with new As-S and Ga-S bond related surface traps located in the midgap-VBM energy range. 